\title{
Breast-conserving therapy for breast carcinoma: Margins, re-excision and recurrence rates
}

\begin{tabular}{|c|c|}
\hline \multicolumn{2}{|c|}{ 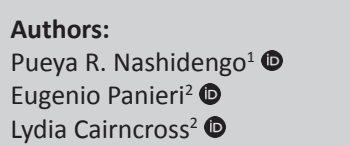 } \\
\hline \multicolumn{2}{|c|}{$\begin{array}{l}\text { Affiliations: } \\
{ }^{1} \text { Department of Surgery, } \\
\text { Groote Schuur Hospital, } \\
\text { University of Cape Town, } \\
\text { South Africa }\end{array}$} \\
\hline \multicolumn{2}{|c|}{$\begin{array}{l}{ }^{2} \text { Oncology and Endocrine } \\
\text { Surgical Unit, Groote Schuur } \\
\text { Hospital, University of Cape } \\
\text { Town, South Africa }\end{array}$} \\
\hline \multicolumn{2}{|c|}{$\begin{array}{l}\text { Corresponding author: } \\
\text { Pueya Nashidengo, } \\
\text { abdrashidn@yahoo.com }\end{array}$} \\
\hline \multicolumn{2}{|c|}{$\begin{array}{l}\text { Dates: } \\
\text { Received: } 21 \text { Oct. } 2017 \\
\text { Accepted: } 25 \text { Nov. } 2017 \\
\text { Published: } 19 \text { Feb. } 2018\end{array}$} \\
\hline \multicolumn{2}{|c|}{$\begin{array}{l}\text { How to cite this article: } \\
\text { Nashidengo PR, Panieri E, } \\
\text { Cairncross L. Breast- } \\
\text { conserving therapy for breast } \\
\text { carcinoma: Margins, } \\
\text { re-excision and recurrence } \\
\text { rates. S. Afr. j. oncol. } \\
\text { 2018;2(0), a31. https://doi. } \\
\text { org/10.4102/sajo.v2i0.31 }\end{array}$} \\
\hline \multicolumn{2}{|c|}{$\begin{array}{l}\text { Copyright: } \\
\text { (c) 2018. The Authors } \\
\text { Licensee: AOSIS. This } \\
\text { is licensed under the } \\
\text { Creative Commons } \\
\text { Attribution License. }\end{array}$} \\
\hline \multicolumn{2}{|l|}{ Read online: } \\
\hline 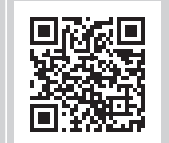 & $\begin{array}{l}\text { Scan this QR } \\
\text { code with your } \\
\text { smart phone or } \\
\text { mobile device } \\
\text { to read online. }\end{array}$ \\
\hline
\end{tabular}

Background: Breast-conserving therapy (BCT) is a wide local excision of the tumour usually followed by radiation treatment to the breast. It is the mainstay treatment for carefully selected patients with early breast cancer. There has not been a formal audit to review BCT outcomes in our unit.

Objectives: To determine excision margins, re-excision and local recurrence rates.

Methods: A histopathological and oncology records' review of BCT patients from 01 January 2006 to 31 December 2010. The health faculty's ethics committee granted approval. Data points accrued included age, histological tumour size, nodal status, tumour type, oestrogen receptor status, lymphovascular invasion, volume of specimen, margin status, management of involved or close margins, radiotherapy, ipsilateral breast recurrence rate and duration of follow-up.

Results: A total of 192 patients had BCT. The mean age is 53 years. A median of $229.5 \mathrm{~cm}^{3}$ volume of specimen was excised. Infiltrating ductal carcinoma was the commonest histological type at $79.1 \%$. The resection margin status: positive margins rate $15.1 \%$, close margin rate $8.3 \%$ ( $\leq 1 \mathrm{~mm}), 35.9 \%$ (1 mm-5 mm), 23.4\% (6 mm-10 mm) and 17.2\% (> $10 \mathrm{~mm})$. Overall, 27 (14.0\%) patients underwent a second procedure, $16(8.3 \%)$ patients had re-excision and $10(5.2 \%)$ patients had a mastectomy. At a median follow-up of 60 months, a total of $11(6.8 \%)$ patients had recurrence. Median time to recurrence is 39 months.

Conclusion: Positive and close margin re-excision and local recurrence rates in our unit are acceptable and comparable to other units in South Africa and internationally.

\section{Introduction}

Breast cancer affects 1 million women in the developed world every year. ${ }^{1}$ The burden of breast cancer is also on the rise in the developing world. According to Jones, ${ }^{2}$ it is estimated that $70 \%$ of new cancer cases will occur in the developing world by the year 2020.

Until the 1970s, the Halsted radical mastectomy had been the surgical procedure in the management of breast cancer irrespective of size. It was described and performed by William Stewart Halsted in $1882 .{ }^{3}$ It included the excision of the skin, the breast and underlying pectoralis muscles. Patients also underwent an axillary lymph node dissection. A skin graft was often used to close the wound defect. Patients were left with morbid disfiguring appearances.

Modified radical mastectomy was shown to be as effectual as radical mastectomy and less mutilating. Modified radical mastectomy remains to be applicable to certain patients. However, breast-conserving therapy (BCT) has become the adopted procedure for the surgical management of early breast cancer. BCT refers to the surgical excision of the primary breast cancer tumour with a rim of normal breast tissue, followed by radiation therapy. It is also referred to in the literature as lumpectomy, partial mastectomy or segmental mastectomy. ${ }^{4}$

Over the past 40 years, prospective large multicentre randomised controlled trials (RCTs) in Europe and United States have provided level 1 evidence that there is no statistically significant difference in the overall long-term survival between mastectomy and $\mathrm{BCT}$ in appropriately selected patients treated for early breast cancer. ${ }^{5}$ Although the overall long-term survival is similar between the two procedures, patients undergoing BCT are at a recognised risk of ipsilateral breast tumour recurrence. ${ }^{6}$ The success rate of BCT relies upon appropriate patient selection, surgical technique and postoperative radiotherapy to eliminate microscopic tumour cells in the ipsilateral breast. The goals of BCT are therefore to resect the tumour with clear microscopic margins and to achieve acceptable cosmetic outcomes without compromising patient survival. 
Breast-conserving therapy has become the standard of care in our oncology and endocrine surgical unit for patients meeting the above criteria diagnosed with early breast cancer at Groote Schuur Hospital. There has not been a formal audit to review the outcomes of BCT in the unit. In South Africa, there has been only one retrospective study on BCT. In 2005, Mannell, a part-time staff member at the University of Witwatersrand, published a retrospective review of 165 patients that underwent $\mathrm{BCT}$ at her private practice at Linksfield and Parklane Clinics over a period of 12 years. In her series, 7 out of 165 patients had re-excision and recurrence at a rate of $5.5 \%{ }^{7}$

\section{Materials and methods}

This is a 5-year histopathological and oncology records' review of consecutive patients who underwent BCT in a specialised unit at Groote Schuur Hospital from 01 January 2006 to 31 December 2010. Inclusion criteria are all the histologically confirmed invasive or in situ breast carcinoma patients. Exclusion criteria are the patients with benign pathological diagnoses, patient with missing folder numbers, patients whose folders could not be found at records and patients lost to follow-up during the study period. Primary endpoints were margin status, rate and type of re-operation and recurrence rate. Secondary outcomes are to identify factors associated with margin status, re-excision and recurrence. Data were retrieved from the unit's prospectively collected patient surgical breast cancer Microsoft Access 2010 database by identifying all the patients that had wide local excisions (WLEs). Additional data were retrieved from patients' folders, National Health Laboratory Service (NHLS) pathology reports and the radiation oncology records.

Data from identified patients were captured using an online password-protected form designed with Google Forms and subsequently transferred onto a spreadsheet. Limiting access and using proxy patient identifiers maintained patient confidentiality.

The following variables were captured: age, pathological tumour size $(\mathrm{pT})$, pathological node status $(\mathrm{pN})$, tumour grade, histological type of tumour, volume of resected specimen $\left(\mathrm{cm}^{3}\right)$, oestrogen receptor (ER) status, presence of lymphovascular invasion, margin status, type of tumour at margin, management of positive margins (re-excision vs mastectomy), type of residual tumour in the resection or mastectomy specimen, radiation therapy post WLE - if completed or not - local recurrence (LR) and time to recurrence, type of tumour and management of recurrence, duration of follow-up at oncology outpatients' department. Extensive intraductal component (EIC) was not recorded, as it did not feature in the NHLS pathology reports.

Tumour grade is described as low, intermediate or high, which is equivalent to 1,2 or 3 , respectively, as per the Nottingham grading system (also called the Elston-Ellis modification of the Scarff-Bloom-Richardson grading system) for breast cancer.
Positive margin is interpreted as the presence of breast cancer, invasive or non-invasive at the inked surgical margin. The absence of tumour within a specified distance of more than 1 $\mathrm{mm}$ or $2 \mathrm{~mm}$ from the resection margin was regarded as a negative margin. A close margin is the presence of tumour within that distance $(1 \mathrm{~mm})$ but not at the resection margin. Volume of specimen is the gross volume of excised cancer with surrounding breast tissue calculated by multiplying height by width by length using the dimensions as described in the pathology report.

The wide local excision procedure in the unit is performed as per standards for BCT. ${ }^{4}$ An elliptical skin incision is followed by excision of the tumour together with circumferential normal breast tissue of $1 \mathrm{~cm}$ to ensure that the resected specimen margins are free of the tumour with tactile perception. The axilla was managed as indicated by clinical or sentinel lymph node biopsy. Lymph node clearance was limited to Level II dissection. LR refers to the first site with histologically proven relapse of invasive or intraductal carcinoma post WLE in the ipsilateral breast.

Statistical analysis was performed using the IBM SPSS Statistics version 22 for Macintosh software. Continuous variables were expressed as means and median as measures of central tendencies and categorical variables as frequencies and percentages. The chi-square test was used to determine the associations between categorical data variables to recurrence.

\section{Results}

Table 1 shows patients and disease characteristics.

The query design for the unit's Microsoft Access database retrieved 242 patients that had procedures recorded as WLEs. Fifty patients were excluded from the study for the following reasons: lost to follow-up (31), incomplete histopathology report (8), benign pathology (3) (benign phylloides 2 and juvenile fibroadenoma 1), diagnostic radio-guided occult lesion localisation (2), incomplete database entry (3) (no name and folder number) and unable to retrieve pathology or oncology records (3).

Therefore, a total of 192 patients underwent BCT in the surgical oncology unit between 01 January 2006 and 31 December 2010 as per inclusion criteria. The patients' age ranged from 25 years to 84 years with a mean age of 53.4 years. More than half of the patients (54.7\%) were above 51 years; $5.2 \%$ of patients were young women who were $<35$ years. The majority of patients (91.7\%) had breast cancers with a maximal diameter of $5 \mathrm{~cm}$. A total of five and four patients had tumours categorised as T3 and T4 by pathology, respectively. Seven patients had WLE post neoadjuvant chemotherapy.

A total of 115 patients (59.9\%) had no pathological nodal involvement ( $\mathrm{pN} 0), 61(29.8 \%)$ had involved nodes ( $\mathrm{pN} 1$ to $\mathrm{pN} 3$ ) and 16 patients (8.3\%) had unknown pathological nodal status $(\mathrm{pNx})$. Low-grade cancer was present in 62 patients 
(32.3\%), intermediate-grade cancer in 77 patients $(40.1 \%)$ and high-grade cancer in 53 patients $(27.6 \%)$. A total of 145 patients $(75.5 \%)$ had absence of lymphovascular invasion and 47 patients $(24.5 \%)$ had presence of lymphovascular invasion.

Two-thirds of patients had ER positive cancers (67.7\%), and $14.1 \%$ of patients had negative ERs. Oestrogen receptor status was not recorded in 35 patients (18.2\%) in the histopathology reports. The Her-2-neu expression was not recorded in 94 patients $(49 \%)$

The commonest histological tumour type was infiltrative ductal carcinoma (IDC) at $79.1 \%$. It was associated with ductal carcinoma in situ (DCIS) in 40.6\%. Infiltrative lobular carcinoma (ILC) was present in $5.3 \%$ followed by DCIS in $3.6 \%$ of the patients.

The median volume of the specimens was $229.50 \mathrm{~cm}^{3}$ with a range of $4 \mathrm{~cm}^{3}$ to $10530 \mathrm{~cm}^{3}$.

\section{Margin status and management}

Of the 192 women who were treated with BCT, 29 had an involved or positive margin after the initial excision (15.1\%).

TABLE 1: Patient and tumour characteristics.

\begin{tabular}{|c|c|c|}
\hline Variable & Number of patients (frequency) & Percentage \\
\hline \multicolumn{3}{|l|}{ Age category (in years) } \\
\hline$\leq 35$ & 10 & 5.2 \\
\hline $36-50$ & 77 & 40.1 \\
\hline$\geq 51$ & 105 & 54.7 \\
\hline \multicolumn{3}{|l|}{ Pathological tumour size } \\
\hline Tis & 7 & 3.6 \\
\hline $\mathrm{T} 1$ & 82 & 42.7 \\
\hline $\mathrm{T} 2$ & 94 & 49.0 \\
\hline T3 & 5 & 2.6 \\
\hline T4 & 4 & 2.1 \\
\hline \multicolumn{3}{|l|}{ Pathological lymph node status } \\
\hline $\mathrm{Nx}$ & 16 & 8.3 \\
\hline NO & 115 & 59.9 \\
\hline N1 & 47 & 24.5 \\
\hline N2 & 9 & 4.7 \\
\hline N3 & 5 & 2.6 \\
\hline \multicolumn{3}{|l|}{ Tumour grade } \\
\hline Low & 62 & 32.3 \\
\hline Intermediate & 77 & 40.1 \\
\hline High & 53 & 27.6 \\
\hline \multicolumn{3}{|l|}{ Lymphovascular invasion } \\
\hline No lymphovascular invasion & 145 & 75.5 \\
\hline Lymphovascular invasion & 47 & 24.5 \\
\hline \multicolumn{3}{|l|}{ ER receptor status } \\
\hline ER positive & 130 & 67.7 \\
\hline ER negative & 27 & 14.1 \\
\hline Unknown & 35 & 18.2 \\
\hline \multicolumn{3}{|l|}{ Excision margins (mm) } \\
\hline Positive & 29 & 15.1 \\
\hline Close $(\leq 1)$ & 16 & 8.3 \\
\hline $1-5$ & 69 & 35.9 \\
\hline $6-10$ & 45 & 23.4 \\
\hline$>10$ & 33 & 17.2 \\
\hline
\end{tabular}

Source: Author's own work.

$E R$, oestrogen receptor.
The commonest pathology at the involved margin was carcinoma in situ at (15 patients) 51.7\%. Sixteen patients $(8.3 \%)$ had a close margin of $<1 \mathrm{~mm}$. Sixty-nine patients (35.9\%) had a margin between $1 \mathrm{~mm}$ and $5 \mathrm{~mm}$. Seventyeight patients $(40.6 \%)$ had a margin of $>6 \mathrm{~mm}$ (Figure 1). Of the patients that had carcinoma in situ at the margins, 8 had repeated WLE, 1 had a mastectomy and 6 had no further surgical intervention. In the infiltrative carcinoma group (14 patients), 6 had a repeated WLE, 2 had mastectomy and 6 had no further surgical intervention (Table 2).

A total of 10 patients had no further surgery for involved margins, 6 and 4 in the DCIS and infiltrative carcinoma groups, respectively. The reasons for no further surgery in the DCIS group were 1 patient developed severe pancreatitis and was lost to follow-up, 4 patients had involved deep margins and 1 patient transferred to another province. In the infiltrative carcinoma group, 1 patient was deemed surgically unfit because of advanced age, 2 patients had tumour at deep margins infiltrating the major pectoralis muscle and we could not determine the reason in the records for 1 patient.

For the women that had a close margin $(<1 \mathrm{~mm}), 5$ and 11 patients had DCIS and infiltrative carcinoma, respectively. In the DCIS group, 3 patients had a subsequent mastectomy and 1 patient each had a repeat WLE and no further surgery because of deep close margins. In the infiltrative close margin group, no patient had a repeat WLE, 2 patients had mastectomy and 9 patients had no further surgery mostly because of deep close margins.

In the group of women who had excision margin $1 \mathrm{~mm}$ to $5 \mathrm{~mm}$, one patient $(6.3 \%)$ had a re-excision for infiltrative

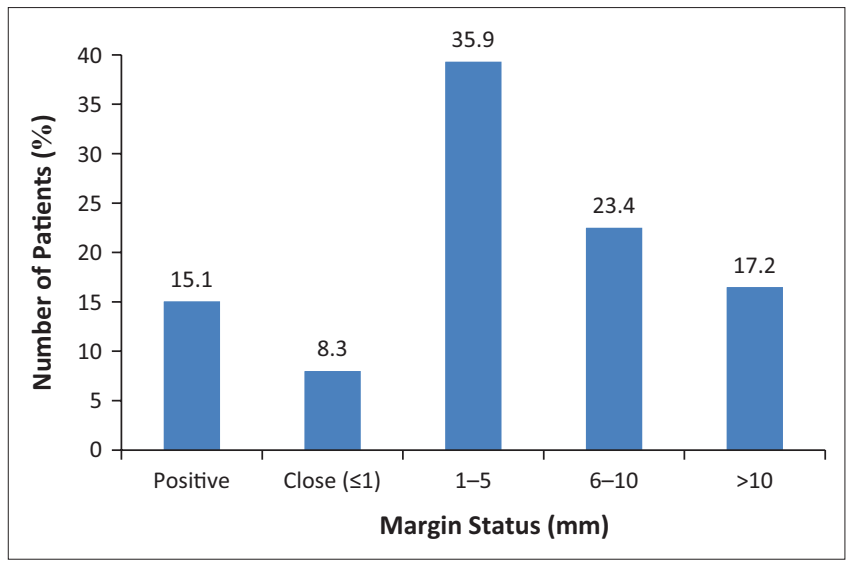

Source: Author's own work

FIGURE 1: Bar chart showing the percentages of the excision margins.

TABLE 2: Excision margins and procedure after initial wide local excision.

\begin{tabular}{lcc}
\hline Excision margin & Re-excision & Mastectomy \\
\hline Positive & $14 / 29$ & $6 / 29$ \\
Close $(<1 \mathrm{~mm})$ & $1 / 16$ & $5 / 16$ \\
$1 \mathrm{~mm}-5 \mathrm{~mm}$ & $1 / 69$ & $0 / 69$ \\
$6 \mathrm{~mm}-10 \mathrm{~mm}$ & $0 / 45$ & $0 / 45$ \\
$>10 \mathrm{~mm}$ & $0 / 33$ & $0 / 33$ \\
\hline Total & $\mathbf{1 6 / 1 9 2}$ & $\mathbf{1 1 / 1 9 2}$ \\
\hline
\end{tabular}

Source: Author's own work 
carcinoma and none had a mastectomy. Neither re-excision nor mastectomy was performed in the women with excision margins of $>6 \mathrm{~mm}$.

A total of 26 patients had subsequent repeat WLE or mastectomy for involved (19 patients), close (6 patients) and $1 \mathrm{~mm}-5 \mathrm{~mm}$ (1 patient) margins, giving an overall re-excision rate of $13.5 \%$. Re-excision rate according to margin status is $9.9 \%$ for positive and $3.1 \%$ for close margins. The rate was similar for DCIS and invasive carcinoma in positive margin group.

A total of 10 patients had mastectomy for involved or close margins giving an overall mastectomy rate of $5.2 \%$ for this study (Table 2).

Residual tumour rate in the re-excision and mastectomy was $50.0 \%$ and $63.6 \%$, respectively. The most common residual histology in both groups was DCIS. One patient that had involved margins in the re-excision specimen had a subsequent mastectomy for persistent margin involved. The histology in this patient was IDC in association with DCIS.

The most significant predictors for re-excision were a positive margin $(p=0.000)$ and the pathological tumour size $(p=0.009)$. The following did not predict re-excision: age $(p=$ $0.825)$, volume of the primary resected specimen $(p=0.148)$, tumour histological grade $(p=0.434)$, tumour ER status $(p=0.786)$ and lymphovascular invasion $(p=0.77)$.

\section{Recurrence}

Local recurrence is hereby defined as the first recurrence of a tumour in the chest wall or in the operative scar in the ipsilateral breast after the initial WLE. During the median follow-up period of 60 months, a total of 11 patients had histologically confirmed recurrence. A total of 31 patients were lost to follow-up during the observational period, giving the relative observed rate of LR of $6.8 \%$. The median time to recurrence was 39 months. All the cases of recurrences were confirmed by histology. Infiltrative ductal carcinoma was the most common histological type of breast cancer at $63.6 \%$ followed by DCIS at $18.2 \%$.

Local recurrence was $6.9 \%$ in patients with histologically positive margins, $5.8 \%$ in patients with $1 \mathrm{~mm}-5 \mathrm{~mm}$ margins, $6.7 \%$ in patients with $6 \mathrm{~mm}-10 \mathrm{~mm}$ margins and $6.1 \%$ in patients with $>10 \mathrm{~mm}$ margins. No recurrence was noted in the close margin group. There was no statistical difference between the resection margins (Pearson's chi-square 0.890).

The total follow-up duration period was calculated from the date of diagnosis to the discharge date or the date the patient was last seen at the oncology clinic at the time of data collection.

Cross tabulation analysis of the rest of the variables such as age of the patient, tumour pathological size, tumour grade, ER status, presence of lymphovascular invasion and completion of radiotherapy post breast-conserving surgery did not show a correlation with LR (Table 3). The Her-2-neu status was not recorded in $49 \%$ of histopathological results and thus not is included in the analysis.

\section{Radiation treatment}

A total of 157 patients $(81.8 \%)$ were referred to the radiation oncology unit for radiotherapy post-surgery, of which $152(96.8 \%)$ completed the radiotherapy course. The total radiotherapy dosages and the patients that received boost radiotherapy dosages were not captured.

\section{Ethical considerations}

Approval for the study was obtained from the University of Cape Town's Faculty of Health Sciences Human Research Ethics Committee (HREC REF: 141/2014).

\section{Discussion}

This study was conducted to review BCT for breast carcinoma in a single tertiary centre. It is the largest study to date

TABLE 3: Effect of different variables on local recurrence.

\begin{tabular}{|c|c|}
\hline Variables & Pearson's chi-square statistic \\
\hline Age (years) & 0.436 \\
\hline \multicolumn{2}{|l|}{$\leq 35$} \\
\hline \multicolumn{2}{|l|}{$35-50$} \\
\hline \multicolumn{2}{|l|}{$\geq 51$} \\
\hline Pathological T stage & 0.684 \\
\hline \multicolumn{2}{|l|}{ Tis } \\
\hline \multicolumn{2}{|l|}{$\mathrm{T} 1$} \\
\hline \multicolumn{2}{|l|}{$\mathrm{T} 2$} \\
\hline \multicolumn{2}{|l|}{ T3 } \\
\hline \multicolumn{2}{|l|}{ T4 } \\
\hline Pathological N stage & 0.850 \\
\hline \multicolumn{2}{|l|}{$\mathrm{Nx}$} \\
\hline \multicolumn{2}{|l|}{ NO } \\
\hline \multicolumn{2}{|l|}{ N1 } \\
\hline \multicolumn{2}{|l|}{ N2 } \\
\hline \multicolumn{2}{|l|}{ N3 } \\
\hline Tumour grade & 0.347 \\
\hline \multicolumn{2}{|l|}{ Low } \\
\hline \multicolumn{2}{|l|}{ Intermediate } \\
\hline \multicolumn{2}{|l|}{ High } \\
\hline Receptor status & 0.173 \\
\hline \multicolumn{2}{|l|}{ ER positive } \\
\hline \multicolumn{2}{|l|}{ ER negative } \\
\hline \multicolumn{2}{|l|}{ ER unknown } \\
\hline Lymphovascular invasion (LVI) & 0.617 \\
\hline \multicolumn{2}{|l|}{ LVI } \\
\hline \multicolumn{2}{|l|}{ No LVI } \\
\hline Radiotherapy completion & 0.960 \\
\hline \multicolumn{2}{|l|}{ Completed } \\
\hline \multicolumn{2}{|l|}{ Not completed } \\
\hline Margin & 0.890 \\
\hline \multicolumn{2}{|l|}{ Positive } \\
\hline \multicolumn{2}{|l|}{$<1 \mathrm{~mm}$} \\
\hline \multicolumn{2}{|l|}{$1 \mathrm{~mm}-5 \mathrm{~mm}$} \\
\hline \multicolumn{2}{|l|}{$6 \mathrm{~mm}-10 \mathrm{~mm}$} \\
\hline$>10 \mathrm{~mm}$ & \\
\hline
\end{tabular}

Source: Author's own work

Level of statistical significance is 0.05 . It is not significant if $>0.05$. $E R$, oestrogen receptor. 
conducted in South Africa. The rate of margin positivity was $15.1 \%$. This rate is comparable to and lower than international studies that vary widely from $3 \%$ to $52 \%$ 7,8,9,10,11,12,13,14,15,16,17 (Table 4). The wide range in positive margin rates internationally is because of a number of factors. These include inconsistent definitions of a positive margin, differences in the use of intraoperative pathological assessment of margins and variations in the handling of surgical specimens and in pathological sampling of margins. The type of surgery also affected these numbers, specifically whether surgery was diagnostic or therapeutic in intent. Also, different studies had a wide range of actual number of surgical resections that were performed to generate the published positive margin rates. ${ }^{18}$

In this study, patients who had tumours with lymphovascular invasion were more likely to have a positive margin (Pearson's chi-square 0.002). Singletary reported that positive margin was significantly associated with large tumour size, young age, axillary node positive status, presence of lymphovascular invasion and an EIC. ${ }^{19}$ Aziz et al. ${ }^{20}$ reported that patients who were younger or had tumours with lymphovascular invasion or a DCIS component were more likely to have a positive margin on a univariate analysis. In this study, the following variables did not predict positive margins: age, pathological tumour size, pathological axillary nodal status, histological diagnosis, grade and ER status.

Nearly, all the tumours in our study are pT1 and pT2 sized $(91.7 \%)$. This is in keeping with international standards and guidelines for BCT for early breast cancer. However, the current trend internationally is that the eligibility of BCT has been expanded to locally advanced breast cancers post neoadjuvant chemotherapy. Primary tumour response rates of approximately $80 \%$ have been observed post neoadjuvant. ${ }^{21}$ Several RCTs have demonstrated the oncologic safety of neoadjuvant chemotherapy for locally advanced breast cancer. The NSABP B-18 trial demonstrated that there was no statistically significant difference in the LR rate following $\mathrm{BCT}$ in the preoperative and postoperative chemotherapy arms. ${ }^{22}$

This practice is not yet adopted in our surgical oncology unit. Although a total of six patients had WLE post neoadjuvant chemotherapy, we postulate that these patients either had large breast to tumour ratio or their tumours were located high on the chest wall or in the inframammary fold that would have rendered a mastectomy difficult.

Positive resection margins have been associated with a higher LR rate. ${ }^{5,10,12,19,23}$ It is a standard practice in our unit to re-excise a positive margin with the intent of achieving clear margin prior to radiation therapy. The decision for reexcision is discussed in a multi-disciplinary team comprising surgeons with special interests in breast cancer, medical and radiation oncologists, histopathologists and radiologists. A variety of factors are taken into consideration before proceeding with re-excision, such as patient's age, comorbidities, life expectancy, extent of excision, extent of margin involvement, tumour characteristics and whether the patient will receive adjuvant treatment. Involved or close margins deep down to fascia are not re-excised because of the morbidity that results from partial muscle excision on the chest wall. Such patients usually receive boost radiation doses.

Our unit's overall re-excision rate of $13.5 \%$ is lower than most international studies. An observational study of 2206 women reported an overall re-excision rate of $22.9 \%$. It is notable that within this study, there were wide substantial variations between surgeons and institutions following BCT. ${ }^{24}$ The most consistent and reliable risk factors for re-excision appear to

TABLE 4: Studies on positive margins and local recurrence by margin status.

\begin{tabular}{|c|c|c|c|c|c|}
\hline \multirow[t]{2}{*}{ Author(s) } & \multirow[t]{2}{*}{ Number of patients } & \multirow[t]{2}{*}{ Positive margins (\%) } & \multicolumn{2}{|c|}{ Local recurrence by margin status ( $\%$ ) } & \multirow[t]{2}{*}{ Follow-up } \\
\hline & & & Negative & Positive & \\
\hline Mannell ${ }^{7}$ & 165 & 6 & - & $5.5 \dagger$ & 65 months median \\
\hline Veronesi et al. (Milan I) ${ }^{8}$ & 1973 & - & 9 & 17 & 6.5-year median \\
\hline Van Dongen et al. (EORTC) ${ }^{9}$ & 431 & - & 9 & 20 & 8-year actuarial \\
\hline DiBiase et al. ${ }^{10}$ & 453 & 19 & 13 & 33 & 120 months \\
\hline Peterson et al. ${ }^{11}$ & 120 & 16 & 8 & 10 & 5-year actuarial \\
\hline Leborgne et al. ${ }^{12}$ & 817 & 6 & 9 & 6 & 9-year actuarial \\
\hline \multirow[t]{2}{*}{ Cowen et al. ${ }^{13}$} & 152 & $48.3^{\mathrm{a}}$ & - & $14^{\mathrm{a}}$ & 5-year crude \\
\hline & & $51.7^{b}$ & & $31 \dagger$ & \\
\hline Dewar et al. ${ }^{14}$ & 663 & 19.9 & 6 & 14 & 10-year actuarial \\
\hline Kini et al. ${ }^{15}$ & 400 & 8 & 6 & 17 & 10-year actuarial \\
\hline Mansfield et al. ${ }^{16}$ & 704 & 15 & 8 & 16 & 120 months \\
\hline Pierce et al. ${ }^{17}$ & 396 & 3 & 3 & 10 & 5-year actuarial \\
\hline \multirow[t]{2}{*}{ Nashidengo (current study) } & 192 & 15.1 & - & $6.1^{c}$ & 60 months median \\
\hline & & & & $5.7^{\mathrm{d}}$ & \\
\hline
\end{tabular}

Source: Modified from Horst KC, Smitt MC, Goffinet DR, et al. Predictors of local recurrence after breast-conservation therapy. Clin Breast Cancer. 2005;5(6):425-438. https://doi.org/10.3816/ CBC.2005.n.0016

Bold values indicate data from this study.

$\dagger$, Local or South African study.

a Recurrence in focal or single positive margin patients.

b, Recurrence in multiple positive margins patients.

c, Recurrence in patients with positive margins in the current study.

d, Overall (i.e. inclusive of positive margins and those that did not have). 
be the presence of micro-calcifications, EIC or DCIS, and lobular histological type. ${ }^{25} \mathrm{~A}$ palpable tumour is more likely to facilitate complete excision, whereas the existence of impalpable [RB.5] DCIS outside the sensible part of the tumour can result in involved resection margin and the subsequent need for a second procedure.

Globally, indications for re-excision for involved or close margins are under constant review. A meta-analysis that included 33 studies and 28162 patients with ipsilateral recurrences supports the use of no ink on the tumour as an adequate negative margin of resection for invasive breast cancer. The authors concluded that there was no evidence that a wider margin of normal breast tissue than no ink on the tumour decreased the rate of recurrence in the clinical setting of multimodality treatment. ${ }^{26}$ Re-excision is therefore not mandatory for close margins $<1 \mathrm{~mm}$ and each case should be individualised.

In our study, the mastectomy rate post the initial WLE for positive margin is $0.5 \%$ and $2.1 \%$ for DCIS and invasive cancer, respectively. For close margins, it is $1.6 \%$ and $1.0 \%$ for DCIS and invasive cancer, respectively. The surgical decision for a re-excision versus a mastectomy is made at a combined breast clinic $(\mathrm{CBC})$. Tumour factors and patient preferences are taken into consideration. Patients with diffuse rather than focally involved margins are offered a mastectomy. A mastectomy is the preferred surgical treatment for multicentric DCIS or persistent positive margin after repeated WLE.

The residual tumour rate in re-excisions and mastectomy groups is $50 \%$ and $63.6 \%$, respectively. These rates are comparable to international studies. ${ }^{19,27,28}$ In our study, the final margin status measurements were not captured, and therefore, we are not able to report the final close margin rate. However, we noted one patient $(0.52 \%)$ who had undergone more than one surgical procedure, a re-excision followed by a mastectomy for persistent positive margin.

The median volume of the excised specimen is $229.5 \mathrm{~cm}^{3}$ in our study. This seems to be larger than the sizes of $60 \mathrm{~cm}^{3}$ and $70 \mathrm{~cm}^{3}$ quoted by Vicini et al. ${ }^{29}$ and Olivotto et al. ${ }^{30}$ The volume of resected breast tissue has a direct impact on cosmesis in breast-conserving surgery. According to Olivotto et al. ${ }^{30}$ tumours $>70 \mathrm{~cm}^{3}$ resulted in a significant increase in the number of cosmetic failures. We postulate that the larger volume reflects the likelihood that our patients presented with slightly larger sized tumours and larger breasts. The cosmetic effects of BCT were not part of this study. A different study in our unit looking into this aspect will provide more insight.

Our study shows a relative observed recurrence of $6.8 \%$ at a median follow-up of 60 months. The recurrence rate in the involved or positive margin patient group is $6.8 \%$. Our LR rate is comparable, if not lower, to international studies that show a LR that varies between $2 \%$ and $13 \%$ for negative margins and $5.5 \%$ and $33 \%$ for positive margins ${ }^{7,9,10,11,12,13,14,15,16,17,23}$
(Table 4). Our data were not sufficient to demonstrate any statistically significant difference between LR and the variables studied.

A total of $156(81.3 \%)$ of the 192 patients that had WLE were referred for radiotherapy. All patients with breast cancer are discussed at the multi-disciplinary team or CBC. At the CBC, the following factors are assessed for BCT for every patient: oncological safety, technical feasibility and delivery of radiotherapy. Contraindications to radiotherapy (previous radiotherapy at this site, connective tissue disorders), if their weight exceeds the radiotherapy weight limit $(140 \mathrm{~kg})$ and whether they are physically able to undergo the treatment in the supine position and can attend 15 sessions of RT. Elderly patients over the age of 80 years are not referred for radiation therapy. In our unit, a total of 40.05 Gy to the chest wall is given over 15 hypofractionated schedules (2.67 Gy). A boost (2.67 Gy in 4 schedules) is given to women $<50$ years or positive margin in whom repeat surgery is not feasible. There were patients that were lost to follow-up after their surgery because of defaulting, some followed up with private radiation oncologists, some moved to other provinces and some declined further treatment. Of the referred patients, $151(96.8 \%)$ completed radiation treatment.

Our study has a number of limitations. Firstly, this was a retrospective study based on the local hospital sample. The database may not have included all the patients that had WLE and incomplete histological reports. We could not access information on non-retrieved folders. This lack of records may have influenced the final outcomes of the study and it reflects the general challenges in the public health sector with regard to poor record-keeping. Therefore, the analysis is subject to selection bias. The recurrence rate was calculated taking into consideration the patients that are lost to follow-up during the observational period. The use of adjuvant systemic therapy and endocrine therapy is not reported. In general, standard regimens for adjuvant chemotherapy in our unit include adriamycin, cyclophosphamide and paclitaxel in patients $<70$ years of age. It would have provided an opportunity to compare the recurrence percentages between arms.

Furthermore, we acknowledge that the $18 \%$ and $49 \%$ of patients without recorded ER and Her-2-neu receptor status is high. This limitation is because of the fact that routine recording of ER and, in particular, human epidermal growth factor receptor 2 (HER-2) receptor status for all patients only became standard practice in our pathology department towards the end of the study period.

\section{Conclusion}

Our study reviews the outcomes of BCT women with early breast cancer in a single tertiary centre. It represents the largest cohort of patients managed at a single institution in South Africa. Apart from the inherent limitation to this retrospective review, the median follow-up period of 60 months is reasonable and provides valuable information 
regarding our unit's surgical margins in BCT, re-excision and ipsilateral breast tumour recurrence rate. The analysis of 192 patients demonstrates outcomes that appear well in keeping with those reported in the international literature with regard to the LR rate.

\section{Acknowledgements}

First and foremost, my heartfelt gratitude goes to Dr Lydia Cairncross, my primary supervisor for this project, for her inspiration, patience, support, input, guidance and advice throughout the research. My gratitude also goes to my cosupervisor Prof. Eugenio Panieri for all his input and guidance. I am also thankful to Miss Nicole van Sens, the research assistant in the Oncology and Endocrine Surgical Unit for assisting with the data collection. In the same vein, I would also like to thank the surgical oncology firm team and the Radiation Oncology Division for the quality of recordkeeping upon which this study depends.

Disclaimer: The views expressed in the submitted article are the author's own and not an official position of the institution.

\section{Competing interests}

The authors declare that they have no financial or personal relationships that may have inappropriately influenced them in writing this article.

\section{Authors' contributions}

P.R.N. was the investigator for this study. E.P was the advisor and co-supervisor for this study. L.C. was the supervisor for this study.

\section{References}

1. Hunt KK, Green MC, Buchholz TA. Diseases of the breast, epidemiology and pathology of breast cancer. In: Townsend CM, Beauchamp RD, Evers BM, Mattox $\mathrm{KL}$, editors. Sabiston textbook of surgery: The biological basis of modern surgical practice. 18th ed. Philadelphia, PA: Saunders Elsevier, 2008; p. 843.

2. Jones SB. Cancer in the developing world: $A$ call to action. BMJ. 1999;319(7208):505-508. https://doi.org/10.1136/bmj.319.7208.505

3. Halsted WS. Original memoirs: The results of radical operations for the cure of carcinoma of the breast. Ann Surg. 1907; XLVI(1):1-19. https://doi.org/10.1097/ 00000658-190707000-00001

4. Morrow M, Strom EA, Bassett LW, et al. Standard for breast-conservation therapy in the management of invasive breast carcinoma. CA Cancer J Clin. 2001;52:277300. https://doi.org/10.3322/canjclin.52.5.277

5. Houssami H, Macaskill $P$, Marinovich ML, et al. Meta-analysis of the impact of surgical margins on local recurrence in women with early-stage invasive breast cancer treated with breast-conserving therapy. Eur J Cancer. 2010;46(18):32193232. https://doi.org/10.1016/j.ejca.2010.07.043

6. Horst KC, Smitt MC, Goffinet DR, et al. Predictors of local recurrence after breastconservation therapy. Clin Breast Cancer. 2005;5(6):425-438. https://doi.org/ 10.3816/CBC.2005.n.001

7. Mannell A. Breast-conserving therapy in breast cancer patients: A 12-year experience. S Afr J Surg. 2005;43(2):28-30.

8. Veronesi U, Cascinelli N, Mariani L, et al. Twenty-year follow-up of a randomized study comparing breast-conserving surgery with radical mastectomy for early breast cancer. N Engl J Med. 2002;347:1227. https://doi.org/10.1056/ NEJMoa020989
9. Van Dongen JA, Voogd AC, Fentiman IS, et al. Long-term results of a randomized trial comparing breast-conserving therapy with mastectomy: European Organization for Research and Treatment of Cancer 10801 trial. J Natl Cancer Inst. Organization for Research and Treatment of Cancer 10801 trial.
2000;92:1143-1150. https://doi.org/10.1093/jnci/92.14.1143

10. DiBiase SJ, Komarnicky LT, Schwartz GF, et al. The number of positive margins influences the outcome of women treated with breast preservation for early stage 1097-0142(19980601)82:11<2212::AID-CNCR16>3.0.CO;2-X

11. Peterson ME, Schultz DJ, Reynolds $C$, et al. Outcomes in breast cancer patients relative to margin status after treatment with breast-conserving surgery and radiation therapy: The University of Pennsylvania experience. Int J Radiat Oncol Biol Phys. 1999;43:1029-1035. https://doi.org/10.1016/S0360-3016(98)00519-7

12. Leborgne $F$, Leborgne $J H$, Ortega $B$, et al. Breast conservation treatment of early stage breast cancer: Patterns of failure. Int J Radiat Oncol Biol Phys. 1995;31:765775. https://doi.org/10.1016/0360-3016(94)00414-5

13. Cowen D, Houvenaeghel G, Bardou V, et al. Local and distant failures after limited surgery with positive margins and radiotherapy for node-negative breast cancer Int J Radiat Oncol Biol Phys. 2000;47:305-312. https://doi.org/10.1016/S03603016(99)00553-2

14. Dewar JA, Arriagada R, Benhamou S, et al. Local relapse and contralateral tumour rates in patients with breast cancer treated with conservative surgery and
radiotherapy (Institut Gustave Roussy 1970-1982). IGR Breast Cancer Group. radiotherapy (Institut Gustave Roussy 1970-1982). IGR Breast Cancer Group.
Cancer. 1995;76:2260-2265. https://doi.org/10.1002/1097-0142(19951201)76: 11<2260::AID-CNCR2820761113>3.0.CO;2-D

15. Kini VR, White JR, Horwitz EM, et al. Long term results with breast-conserving therapy for patients with early stage breast carcinoma in a community hospital therapy for patients with early stage breast carcinoma in a community hospital
setting. Cancer. 1998;82:127-133. https://doi.org/10.1002/(SICI)1097-0142 setting. Cancer. 1998;82:127-133. https://d
(19980101)82:1<127::AID-CNCR15>3.0.CO;2-4

16. Mansfield CM, Komarnicky LT, Schwartz GF, et al. Ten-year results in 1070 patients with stages I and II breast cancer treated by conservative surgery and radiation therapy. Cancer. 1995;75:2328-2336. https://doi.org/10.1002/1097-0142 therapy. Cancer. 1995;75:2328-2336. https://doi.org/
(19950501)75:9<2328::AID-CNCR2820750923>3.0.CO;2-L

17. Pierce LJ, Strawderman $M H$, Douglas $K R$, et al. Conservative surgery and radiotherapy for early-stage breast cancer using a lung density correction: The University of Michigan experience. Int J Radiat Oncol Biol Phys. 1997;39:921-928. https://doi.org/10.1016/S0360-3016(97)00464-1

18. Lovrics PJ, Cornacchi SD, Farrokhyar F, et al. The relationship between surgical factors and margin status after breast-conservation surgery for early stage breast cancer. Am J Surg. 2009;197:740-746. https://doi.org/10.1016/j.amjsurg.2008. 03.007

19. Singletary SE. Surgical margins in patients with early-stage breast cancer treated with breast conservation therapy. Am J Surg. 2002;184:383-393. https://doi. org/10.1016/S0002-9610(02)01012-7

20. Aziz D, Rawlinson E, Narod SA, et al. The role of re-excision for positive margins in optimizing local disease control after breast-conserving surgery for cancer. Breast J. 2006;12(4):331-337. https://doi.org/10.1111/j.1075-122X.2006.00271.x

21. Newman LA, Washington TA. New trends in breast conservation therapy. Surg Clin North Am. 2003;83:841-883. https://doi.org/10.1016/S0039-6109(03)00029-X

22. Fisher B, Brown A, Mamounas $E$, et al. Effect of preoperative chemotherapy on local-regional disease in women with operable breast cancer: Findings from National Surgical Adjuvant Breast and Bowel Project B-18. J Clin Oncol. 1997;15:2483-2493. https://doi.org/10.1200/JCO.1997.15.7.2483

23. Veronesi $U$, Salvadori B, Luini A, et al. Breast conservation is a safe method in patients with small cancer of the breast. Long-term results of three randomized trials on 1,973 patients. Eur J Cancer. 1995;31A:1574-1579. https://doi.org/ 10.1016/0959-8049(95)00271-J

24. McCahill LE, Single RM, Aiello Bowles EJ, et al. Variability in re-excision following breast conservation surgery. JAMA. 2012;307:467-475. https://doi.org/10.1001/ jama.2012.43

25. Dietrich $M$, Dieterich $H$, Moch $H$, et al. Re-excision rates and local recurrence in breast cancer patients undergoing breast conserving therapy. Geburtshilfe Frauenheilkd. 2012;72(11):1018-1023. https://doi.org/10.1055/s-0032-1327980

26. Moran MS, Schnitt SJ, Giuliano AE, et al. Society of Surgical Oncology-American Society for Radiation Oncology consensus guideline on margins for breast-
conserving surgery with whole-breast irradiation in stages I and II invasive breast conserving surgery with whole-breast irradiation in stages I and II invasive breast
cancer. Ann Surg Oncol. 2014;21:704. https://doi.org/10.1245/s10434-014-3481-4

27. Papa MZ, Zippel D, Koller M, et al. Positive margins of breast biopsy: Is re-excision always necessary? J Surg Oncol. 1999;70:167-171. https://doi.org/10.1002/ always necessary? J Surg Oncol. 1999;70:167-171. h
(SICI)1096-9098(199903)70:3<167::AID-JSO4>3.0.CO;2-7

28. Gwin JL, Eisenberg BL, Hoffman JP, et al. Incidence of gross and macroscopic carcinoma in specimens from patients with breast cancer after re-excision lumpectomy. Ann Surg. 1993;218:729-734. https://doi.org/10.1097/00000658199312000-00005

29. Vicini FA, Kestin LL, Goldstein NS, et al. Impact of young age on outcome in patients with ductal carcinoma-in-situ treated with breast-conserving therapy. J Clin Oncol. 2000;18:296-306. https://doi.org/10.1200/JCO.2000.18.2.296

30. Olivotto I, Rose MA, Osteen RT. Late cosmetic outcome after conservative surgery and radiotherapy: Analysis of causes of cosmetic failure. Int J Radiat Oncol Bio Phys. 1989;17:747-753. https://doi.org/10.1016/0360-3016(89)90061-8 